
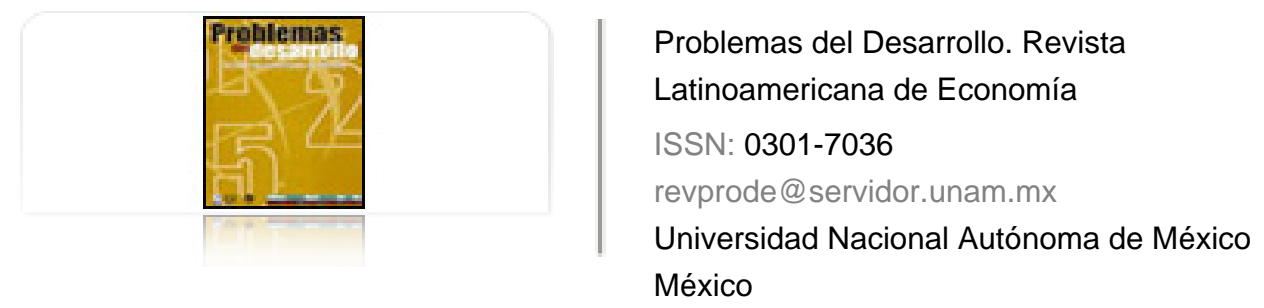

Veltmeyer, Henry

LA CRISIS GLOBAL Y LATINOAMÉRICA

Problemas del Desarrollo. Revista Latinoamericana de Economía, vol. 41, núm. 160, enero-marzo, 2010, pp. 13-38

Universidad Nacional Autónoma de México

Distrito Federal, México

Disponible en: http://www.redalyc.org/articulo.oa?id=11820132002

- Cómo citar el artículo

- Número completo

- Más información del artículo

Página de la revista en redalyc.org

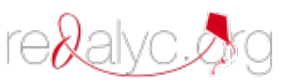

Sistema de Información Científica

Red de Revistas Científicas de América Latina, el Caribe, España y Portugal Proyecto académico sin fines de lucro, desarrollado bajo la iniciativa de acceso abierto 


\title{
LA CRISIS GLOBAL Y LATINOAMÉRICA
}

\author{
Henry Veltmeyer*
}

Fecha de recepción: 22 de octubre de 2009. Fecha de aceptación: 12 de febrero de 2010.

\section{Resumen}

Este trabajo proporciona una perspectiva crítica sobre la actual crisis global en sus dinámicas en América Latina. Se rebate el argumento central que prevalece tanto en revistas de divulgación como académicas respecto de que la crisis es un fenómeno fundamentalmente financiero, precipitado por la falta de regulación de capital y una ola de especulación financiera, que se puede resolver con la construcción de un nuevo arreglo financiero, más eficaz y sujeto a una mejor gobernabilidad global. Sin embargo, nuestro argumento es que en el contexto de América Latina se trata de una crisis del sistema y del modelo vigente, que requiere una respuesta diferente a las que predominan en el ámbito político en la región.

Palabras clave: crisis, capital global, financiarización, gobernabilidad global, regulación, régimen político, movimientos sociales.

* Profesor investigador de la Unidad de Estudios del Desarrollo de la Universidad de Zacatecas. Correo electrónico: hveltmeyer@gmail.com.

Traducción del inglés: Edgar Zayago Lan. 


\section{Abstract}

This study provides a critical perspective of the current global crisis in its Latin America dynamic. It refutes the central argument or the one that prevails both in popular and academic magazines that the crisis is a fundamentally financial phenomenon, precipitated by a lack of regulation of capital and a wave of financial speculation, that can be resolved by the construction of new financial arrangements, which are more efficient and subject to better global governance. But our argument is that in the context of Latin America we are dealing with a crisis of the system and of the prevailing model, which requires a different response to those predominating in the region's political orbit.

Key words: crisis, global capital, "financialization", global governance, regulation, political regime, social movements.

\section{Résumé}

Ce travail fournit une perspective critique de l'actuelle crise globale à partir de ses dynamiques en Amérique latine. Il y est réfuté l'argument central qui prévaut tant dans les revues de vulgarisation que dans les publications académiques, selon lequel la crise est un phénomène fondamentalement financier, précipité par le manque de régulation du capital et une vague de spéculation financière, auquel on peut mettre fin en construisant un nouveau pacte financier plus efficace et propice à une meilleure gouvernabilité globale. Au contraire, notre argument est que, dans le contexte de l'Amérique latine, il s'agit d'une crise du système et du modèle en vigueur, qui requière une réponse différente à celles qui sont en général prônées dans le milieu politique de la région.

Mots clés: crise, capital global, financiarisation, gouvernabilité globale, regulation, régime politique, mouvements sociaux.

\section{Resumo}

Este trabalho proporciona uma perspectiva crítica sobre a atual crise global em suas dinâmicas na América Latina. Rebate-se o argumento central que prevalece tanto em revistas de divulgação como acadêmicas no sentido de que a crise é um fenômeno fundamentalmente financeiro, precipitado pela falta de regulação de capital e uma onda de especulação financeira, que pode resolver-se com a construção de um novo arranjo financeiro, mais eficaz e sujeito a uma melhor governabilidade global. No entanto, nosso argumento consiste em que, no contexto da América Latina, trata-se de uma crise do sistema e do modelo vigente, que requer uma resposta diferente das que predominam no âmbito político na região.

Palavras-chave: crise, capital global, financiarização, governabilidade global, regulação, regime político, movimientos sociais. 


\section{Introducción}

1 objetivo de este ensayo es proporcionar una perspectiva crítica sobre la actual
crisis financiera mundial, dando énfasis a sus dinámicas en América Latina.
En el último año se han publicado varios libros y numerosos artículos tanto en revistas de divulgación como académicas, explicando la crisis desde una misma perspectiva: como resultado de la falta de regulación financiera y de la especulación irresponsable. El argumento central de dichos textos es que la crisis, precipitada por la debacle de las hipotecas subprime, se relaciona con políticas que promovieron una ola de especulación financiera, mientras que los prestamistas y los financieros encontraron la manera de explotar la falta de regulación. En otras palabras, se establece que la crisis no es sistémica o estructural, sino financiera y, por lo tanto, susceptible de ser corregida mediante una política monetaria adecuada y la construcción de un nuevo arreglo financiero, más eficaz y sujeto a una mejor gobernabilidad global.

En este ensayo discrepamos de esta postura y sostenemos que la crisis es parte del sistema, lo que se evidencia en el hecho de que con anterioridad ya han ocurrido muchas crisis, aunque esta última haya sido la más violenta, por lo que se pone claramente de manifiesto la propensión estructural a la crisis. Sin embargo, esta crisis, que se transforma rápidamente de un fenómeno financiero a una crisis de múltiples dimensiones, no es uniforme en sus impactos a escala mundial o regional. Debido a las coyunturas particulares de América Latina, se presentan diversas respuestas a la crisis, consolidadas desde el sector popular y que muestran una posible salida al desastre. Una salida que va más allá de los mercados, de la supervisión de los banqueros, de la regulación eficiente de capital e, incluso, del capitalismo mismo. Estas respuestas buscan enfrentar tanto a la estructura institucional como a los pilares de la misma estructura que, reiteramos, mantiene una tendencia natural a la crisis.

Para tal propósito, construimos nuestro argumento en cuatro partes. En primer lugar, establecemos la premisa de nuestro argumento: el capitalismo se caracteriza por una tendencia inherente hacia la crisis. Posteriormente, revisamos las publicaciones más recientes que explican la crisis, de las cuales extraemos dos posturas básicas: una monetaria y otra estructural; esta segunda postura ofrece una explicación más cercana a la realidad, es decir, sobre las raíces mismas de la crisis. De allí pasamos a explorar la dinámica de la crisis en su contexto y en la forma en que se está desarrollando en América Latina. En esta sección nos enfocamos en las diversas respuestas dadas a la crisis, más que en sus efectos en la economía y la sociedad. En la siguiente parte examinamos las alternativas populares y las respuestas que están surgiendo en la región. Una de las conclusiones a las que llegamos es que ni la des- 
financiarización ni la regulación del capital global en su forma especulativa, ni los nuevos controles sobre la codicia y las fuerzas de la "libertad económica", ni una política contracíclica a la crisis con la restauración de crédito o un plan de estímulo de producción serán suficientes para resolver el problema ${ }^{1}$. Otra conclusión es que éste es el momento preciso para avanzar más allá del capitalismo regulado hacia el socialismo en alguna forma. Finalmente planteamos que la agencia más adecuada para esta transición-que nos lleve a salir de la crisis- es la activa movilización de las fuerzas de cambio en el sector popular de la sociedad. En este contexto, creemos que los avances en América Latina están señalando el camino a seguir.

\section{Una propensión a la crisis}

A pesar de las diversas explicaciones sobre la crisis financiera y económica ${ }^{2}$, los patrones de desarrollo económico y político de las últimas cuatro décadas se suscriben a la tendencia que tiene el sistema capitalista mundial hacia la crisis. Alguna vez (antes de la década de 1990) hubo dos sistemas de producción, capitalista y socialista-cada uno con tres diferentes "niveles de desarrollo" (Worsley, 1984). Pero por razones diversas, que hasta ahora no tienen una explicación satisfactoria $-\mathrm{y}$ que requieren

1 La OIT ha realizado un estudio sobre los planes de estímulo donde considera que la mayoría de los países del G-20 han elaborado algún tipo de paquete llegando a aproximadamente US \$2 billones. Por definición, para algunos, todos estos planes son de naturaleza contracíclica, diseñados para aumentar el gasto para estimular la demanda. Estos planes se originan en los países desarrollados o en países en vías de desarrollo muy grandes, como China o la India. El plan de los EEUU de US \$787 millardos consiste en recortes fiscales y apoyo a la infraestructura, fondos para la asistencia a la salud y para la energía verde. El plan de estímulo de China de US \$586 millardos (mayor que el de EEUU en términos del PIB) se destina a infraestructura, a desastres y a programas de protección para las industrias automotriz, de astilleros y electrónica. Como se ha mencionado, el gran monto inyectado a la economía de los países que conforman el G-8 se ha destinado a impulsar los mercados y para restituir los US $\$ 50$ billones que fueron borrados del mundo financiero en el transcurso del año pasado. Pero es probable que este monto tenga un alza, quizá por un factor de dos o tres, ya que los banqueros seguirán reteniendo el crédito, es decir, sin poner en riesgo su capital en los mercados de valores, lo que augura la no recuperación en los próximos dos o tres años, por lo que el sistema en su conjunto seguirá sufriendo los efectos de la crisis de la producción hasta que se derrumbe o salga airoso de nueva cuenta.

2 Irónicamente, fue Alan Greenspan, en 2007, recientemente "retirado" del servicio como presidente del Banco Central (la Reserva Federal o Fed) de los EEUU, quien advirtió sobre la inminente recesión económica de su país y su posible repercusión mundial. La ironía radica en que precisamente fue él quien desempeñó un papel central en la creación del sistema financiero que hizo inevitable la crisis mundial. Bajo la dirección de Robert Rubin y Lawrence Summers, el Tesoro de los EEUU cooperó con la Reserva Federal de Alan Greenspan para liberalizar sustancialmente al sistema financiero. 
un análisis posterior más adecuado-, el socialismo, presentado como alternativa al capitalismo, sucumbió a una crisis sistémica y política, que terminó desmoronando el socialismo de la URSS, de Europa oriental, de China y de otras partes de Asia (Desai, 2004) $)^{3}$.

En el caso del socialismo en África, se puede decir que nunca fue más que una idea, ya que al parecer las condiciones para su práctica nunca estuvieron disponibles (véase Friedland y Rosberg, 1964) ${ }^{4}$. Cuba, una víctima de las condiciones derivadas de este colapso, logró por su cuenta reestructurar su modelo socialista y sobrevivir a la crisis del modelo en otros países, lo que motivó una recuperación lenta pero estable, que ha perdurado por más de una década de reforma económica y vinculada al nuevo contexto de la globalización (Bell Lara, 2009).

En cuanto a los otros países de la región, se puede decir que han tenido que sufrir los efectos de las diversas fuerzas destructivas del sistema y de su configuración neoliberal. Walden Bello argumenta (2009) que es posible trazar los orígenes de la crisis sistémica que azota al mundo capitalista, desde la década de 1970, es decir, desde la crisis que puso fin a la Era de Oro del Capitalismo, a la que los historiadores franceses llaman los Treinta Años Gloriosos (1945-1975). El acelerado ritmo, mayor en número aunque no en duración, de las crisis de sobreproducción en el capitalismo después de esta "era dorada", se ha manifestado en una tendencia hacia el estancamiento, desatando procesos de reestructuración que han conducido a los siguientes resultados ${ }^{5}$ :

- una conversión tecnológica del aparato productivo mundial, promoviendo un proceso de "transformación productiva" (ECLAC, 1990);

3 En cuanto al socialismo de modelo soviético se puede argumentar que, evidentemente, su colapso no era sólo una cuestión de crisis política, sino económica, debido quizá a dos aspectos "estructurales" del modelo: 1) su incapacidad de incorporar al aparato de producción los avances tecnológicos; 2) un límite fatal en la productividad, un tardío desarrollo a causa del sistema de planificación central; y, relacionado con esto 3) la confusión en el mercado y en el sector privado con el capitalismo y, por lo tanto, como Cuba en su ofensiva revolucionaria en 1968, su abandono.

4 No existe una definición precisa del socialismo africano. Incluso los líderes africanos que en 1962 se reunieron en Dakar, Senegal, para examinar el tema, no llegaron a una definición clara del concepto (Friedland y Rosberg Jr., 1964). El socialismo africano no es más que un conglomerado de ideas sobre el socialismo avanzado por diferentes líderes políticos africanos. En consecuencia, no representa una precisión unificada; se trata, más bien, de una singularidad motivada por una orientación ideológica, o de una guía para la acción.

5 Para un argumento más extendido sobre este punto, véase Petras y Veltmeyer, 2001. 
- un desplazamiento mundial, espacial y geográfico de producción y de capital, dando lugar al fenómeno de los países de reciente industrialización, localizados en algunas latitudes del Sur global, y a una nueva división internacional del trabajo (Fröbel, Heinrichs y Kreye, 1980);

- una reestructuración institucional con la intención de vigorizar el sistema capitalista mundial, reconfigurando la forma de tomar decisiones respecto a la asignación de recursos productivos, "independizando" aún más a las fuerzas económicas y liberándolas de los candados del Estado de bienestar y desarrollador (Petras y Veltmeyer, 2001; 2005);

- una política de reestructuración (contrarrevolución neoconservadora) que disminuyó el poder del Estado y, a la vez, destruyó el poder de los trabajadores sindicalizados en su relación con el capital, lo que resultó en descentralización y redemocratización para, de esta manera, compartir la responsabilidad de la gestión pública con amplios sectores de la sociedad civil (Veltmeyer, 2007) ${ }^{6}$; y

- a partir de finales del decenio de 1980, un proceso de financiarización, que originó un enorme desfase entre la economía real y la financiera y, en 2007, una grave crisis del sistema financiero, que causó la implosión y el derrumbe de las inversiones mundiales de capital. Lo anterior amenaza con hundir la economía real y, como resultado, sacudir los cimientos de la producción capitalista mundial, con una fuerte contracción de la economía real en el centro del sistema y, todavía, con consecuencias inesperadas en la periferia (Foster y Magdoff, 2008).

Walden Bello entiende el proceso vivido desde 1980 como un ajuste económico y político del nuevo orden mundial, el cual tenía tres estrategias para escapar de la crisis de sobreproducción: 1) la reestructuración neoliberal, 2) la globalización y 3) la financiarización.

La reestructuración neoliberal, según Bello, tomó la forma de thatcherismo y de reaganismo en el Norte, y de ajuste estructural en el Sur. El objetivo, prosigue el mismo autor, era "fortalecer la acumulación de capital" mediante: a) "la eliminación de la participación del Estado en el crecimiento económico y en el uso y flujo de capital", y $b$ ) la redistribución de los ingresos de los pobres y de las clases medias hacia los ricos, con la idea de que los ricos serían motivados a invertir y, así, reiniciar el proceso de crecimiento económico. De acuerdo con Bello, el problema

6 Este punto es discutible. Sin embargo, para un argumento más extendido al respecto, véanse Petras y Veltmeyer, 2009; Veltmeyer, 2007. 
de esta fórmula "es que la redistribución de los ingresos hacia los ricos [...] resultó en una restricción de la demanda y de la capacidad de compra de los pobres y clases medias, por lo que no se indujo a los ricos a invertir y a elevar la producción"7. Como resultado, la reestructuración neoliberal, generalizada en el Norte y en el Sur durante la décadas de 1980 y 1990, tuvo un impacto negativo en términos de crecimiento económico: "el crecimiento global promedio fue de $1.1 \%$ en el decenio de 1990 y de $1.4 \%$ en el decenio de 1980, en comparación con el $3.5 \%$ en el de 1960 y el $2.4 \%$ en el decenio de 1970 , cuando las políticas intervencionistas eran dominantes".

La segunda "vía de escape" y mecanismo de acumulación del capital global era una acumulación extensiva, entendida como globalización -"la integración de las áreas semicapitalistas, no capitalistas o precapitalistas a la economía de mercado mundial". El objetivo, como Bello lo entiende, fue facilitar al capital el acceso a mano de obra barata, así como a mercados nuevos y fuentes baratas de materias primas. La integración se lograba mediante diversas medidas como la eliminación de los obstáculos a la movilidad del capital, la supresión de barreras a la inversión extranjera y, principalmente, la liberalización financiera y comercial. Estas últimas políticas eran centrales en los programas neoliberales promovidos por el Consenso de Washington.

La alternativa para salir de la crisis en realidad terminó exacerbando el problema de la sobreproducción, porque la solución se centraba en incrementar la capacidad productiva. Por ejemplo, "China experimentó un gran auge en su capacidad de producción durante los últimos 25 años, con un efecto depresor sobre los precios y la ganancia en otras partes del sistema". Bello argumenta que no es de extrañar que alrededor de 1997 las ganancias de las empresas de los EEUU simplemente dejaran de crecer. Según un

7 Para Bello, "los ricos" refiere a los banqueros y financieros, a los encargados de financiar a los capitalistas, aquellos que, como bien explican Magdoff y Sweezy (1998) y Foster y Magdoff (2008), son los que se resisten o no quieren invertir bajo el contexto de una "crisis de insolvencia" en la que "el balance de capital de las instituciones financieras ha sido arrasado". El problema a nivel macro, como Foster y Magdoff (2008: 8) describen, es la magnitud de la deuda total del capital invertido (mayormente capital especulativo), que en la última década ha crecido a un nivel totalmente insostenible, tan sólo en los EEUU creció de alrededor de $150 \%$ del PIB en 1960 a 373\% del PIB en 2007 (aproximadamente US \$51.3 billones).

8 El estancamiento general de la ganancia que Bello muestra se refiere únicamente a las inversiones productivas en la economía real. En contraste, Foster y Magdoff (2008) construyen e interpretan los datos de la tasa global de la "ganancia financiera" que literalmente se disparó de 1997 a 2005, ya que este índice pasó de alrededor de 1300 a más de 3 000, mientras que en 1970 era igual a 100 . 
cálculo hecho por la revista Fortune 500, la tasa de ganancia de las empresas pasó de $7.2 \%$ entre 1960 y 1969 a $5.3 \%$ entre 1980 y $1990 ;$ a $2.3 \%$ entre 1990 y 1999 y a $1.3 \%$ entre 2000 y 2002. A finales de los noventa, ya con un exceso de inventario en casi todas las industrias, la brecha entre la capacidad de producción y de ventas era comparable con la Gran Depresión, aunque en cambio crecieron las ganancias del sector financiero, compensando esa baja -y cambiando las dinámicas actuales y precisas de la crisis.

Por los pobres resultados obtenidos contra el impacto depresivo de la sobreproducción, la tercera vía de escape, es decir, la financiarización, llegó a ser crítica para mantener y aumentar la tasa de ganancia. Con la inversión en la industria y la agricultura generando poca ganancia, como resultado del exceso de capital acumulado, grandes cantidades de fondos excedentes fueron invertidas o dirigidas hacia el sector financiero, profundizando el problema e incrementando la especulación, es decir, "el sector financiero terminó volviéndose en contra de sí mismo" (Bello, 2009).

El resultado fue la profundización de la brecha entre la economía financiera inflada y la economía real estancada. Por lo que recientemente un ejecutivo del Financial Times señaló: "ha habido una creciente desconexión entre la economía real y financiera en los últimos años. La economía real ha crecido [...] pero nada comparable con el crecimiento de la economía financiera, hasta que esta última implosionó"”.

La reestructuración multidimensional (para escapar de la crisis) puede ser trazada en cuatro décadas de "desarrollo". Un proceso en donde se pasó de un Estado de bienestar-desarrollador a un Estado puramente neoliberal, aunque vale decir, con una muy "breve historia del neoliberalismo" (Harvey, 2005). Dicha breve historia se puede sintetizar en cuatro ciclos de desarrollo (Petras y Veltmeyer, 2009):

1. Un proceso vinculado a las políticas diseñadas en la década de 1970 por una nueva generación de economistas formados en Chicago, y simpatizantes de conformidad con el régimen militar de Augusto Pinochet.

2. Otro ciclo tomó lugar en la década de 1980, en una convocatoria para formar un nuevo orden mundial (OMN) en el que Thatcher, Reagan y otros neoconservadores aplicaron programas de reformas "estructurales" de la política económica nacional (diseñados por economistas desde el Banco Mundial y tomando como base el modelo del régimen de Pinochet, respaldado por el Consenso de Washington). Todo esto bajo las condiciones de una crisis ocasionada por la deuda externa.

9 Citado en Bello, 2009. Para un análisis más agudo sobre las dinámicas de la implosión financiera, véase Foster y Magdoff, 2008. 
3. Otro fue marcado por una tercera ronda de las reformas neoliberales en la década de 1990, y tuvo lugar a partir de un Posconsenso de Washington, construido sobre la necesidad de crear un neoliberalismo más incluyente, sostenible y gobernable. En otras palabras, para crear un mejor equilibrio entre el Estado y el mercado en el proceso de desarrollo (véase, en particular, Ocampo, 2006; 2007).

4. Por último, observamos el ciclo del nuevo milenio con una enorme burbuja financiera que superó exponencialmente el crecimiento de la economía real, y el aumento del consumo de materias primas (2003-2008), impulsado por la demanda de energéticos por parte de China y la India ${ }^{10}$.

\section{Repensando la crisis}

Las dinámicas y las causas de la crisis en el sistema de producción capitalista son evidentes ${ }^{11}$. Las mismas han sido esbozadas con anterioridad por una larga serie de investigadores que retoman los análisis de Marx sobre la propensión inherente del capitalismo a la crisis (Magdoff y Sweezy, 1988; Foster y Magdoff, 2008). Entonces ¿qué hay de diferente y nuevo en la crisis actual? La respuesta no está en la profundidad o el alcance global de la crisis, sino en sus múltiples formas y dimensiones, la económica, la de sobreproducción, la de la reglamentación del trabajo (fordismo), la del acceso a los alimentos y la energía, la encontrada en el medio ambiente, y en las diferentes formas sociales y políticas ${ }^{12}$. Es evidente que esta crisis multidimensional está profundamente arraigada en la estructura económica y social del sistema capi-

10 Para un análisis de las implicaciones para el caso latinoamericano, véase Petras y Veltmeyer, 2009.

11 En general, se entiende que la causa de la actual crisis financiera mundial fue la burbuja en el sector inmobiliario de los EEUU, ya que muchas personas fueron incapaces de cubrir las cuotas mensuales de sus hipotecas. Sin embargo, casi todos están de acuerdo en que la crisis es más profunda y que está muy arraigada en la estructura de la economía, como señaló Marx y posteriormente otros académicos marxistas han afirmado en Monthly Review. En contraste, se plantea que la crisis es un fracaso de la política monetaria derivada de la desregulación financiera, como Milton Friedman explicaba sobre la Gran Depresión, o como al inicio de esta crisis lo hizo Bernanke (el entonces jefe del Consejo de Asesores Económicos y de la Reserva Federal, que reemplazó a Alan Greenspan en el gobierno de George W. Bush).

12 De acuerdo con Guillén (2009), la crisis global es una crisis tanto inédita como multifacética. Señala que en su dimensión económica y financiera, es sólo "uno de los cuatro procesos de crisis que enfrenta el mundo en la actualidad. Junto a ella se entrelazan otros procesos iguales o más importantes, como la crisis ecológica (donde destacan los problemas derivados del calentamiento del planeta); la crisis energética, que señala los límites de un paradigma energético y de un modo de consumo basado en el uso y abuso de los combustibles fósiles; y la crisis alimentaria". 
talista mundial y, en este sentido, puede ser descifrada desde la teoría marxista de la dinámica del desarrollo capitalista.

Desde esa perspectiva, el capitalismo está avanzando claramente hacia una nueva fase y las medidas tomadas para controlar la crisis sugieren la reestructuración de las condiciones que faciliten la acumulación de capital. No obstante, es posible que dichas condiciones puedan conducir a la caída o el derrocamiento del sistema sin promover una nueva reestructuración. Pero, ¿acaso cabe la posibilidad, considerando la resistencia del sistema y los diversos mecanismos de respuesta de la crisis, que a pesar de su profundidad y alcance mundial, ésta pueda dar lugar a un nuevo proceso de acumulación de capital? Al igual que la crisis en sí, es probable que la nueva configuración sea multidimensional tanto en la forma económica (reforma neoliberal, globalización, financiarización, conversión tecnológica) como en su forma política, lo anterior, por la relación necesaria entre estructura y superestructura.

En cuanto a la dimensión política del sistema capitalista, la clave para su supervivencia puede estar en el intento por contraer el poder de decisión sobre la producción de la base capitalista, es decir, que se monopolice la toma de decisiones relacionada con la asignación de los recursos productivos, y aquellas que tengan que ver con la distribución de la riqueza social. En la crisis anterior y en su respectiva reestructuración (1970-1990), los límites de las fuerzas de la producción del capitalismo fueron superados mediante un proceso dirigido exclusivamente por el Estado, vinculado a una forma de distribución del bienestar (Glynn, Hughes, Lipietz y Singh, 1990).

En el contexto de globalización neoliberal, esos mismos límites políticos han dado lugar a un Posconsenso de Washington, preocupado por crear una forma de neoliberalismo más inclusivo, así como nuevas maneras de promover la gobernabilidad local y mundial. Ha habido otros intentos para reformar el neoliberalismo, como el resurgimiento de la democracia social y el intento pragmático para equilibrar la acción del Estado y del mercado en el proceso de desarrollo capitalista. Queda por ver si esta nueva forma política de neoliberalismo pragmático, que algunos denominan posliberalismo, puede ser utilizada para contener las fuerzas de la resistencia y para reestablecer el supuesto orden.

\section{La dinámica de la crisis en América Latina}

Entre 2003 y 2008 América Latina -en particular América del Sur-, encontró una salida a la crisis de producción que azotó a la región en 2001-2002 ${ }^{13}$. Algunos de estos

13 A raíz de las ataques terroristas del 11 de septiembre, el crecimiento de América Latina disminuyó más que en cualquier otra región en desarrollo, éste pasó de un crecimiento real del PIB 
países experimentaron una ola de crecimiento a partir de la exportación de materias primas, fuentes de energía, minerales y otros insumos industriales con destino a Asia, particularmente China, así como de bienes de consumo manufactureros para la clase media de los países del Centro ${ }^{14}$. En el transcurso de esta bonanza, la tasa de crecimiento económico pasó de una tasa regional promedio de $0.6 \%$ en 1996 y apenas $1 \%$ en 2002 a una media regional de $6.2 \%$ en 2004, 5.5\% en 2005 y $5.6 \%$ en 2006. En los países de América del Sur, el auge en el crecimiento a partir de 2003 y hasta 2007 fue aún mayor-como promedio anual fue de $8.3 \%$ en Argentina, $8.0 \%$ en Venezuela, $6.3 \%$ en Perú y $3.9 \%$ en Bolivia, y en la Cuba socialista la tasa de crecimiento anual fue de 9.0\% (CEPAL, 2007: 85; CEPAL, 2008: 13).

En 2008, este auge de exportación de materias primas desapareció en el vórtice de la crisis financiera ${ }^{15}$. La primera respuesta a esta crisis, en el ámbito gubernamental, fue negarla - tal es el caso de México, cuyo presidente, Felipe Calderón, sostuvo en la Cumbre Económica de Davos que América Latina y en particular México eran inmunes al virus financiero y podían sobrellevar "el resfriado" sin muchos problemas ${ }^{16}$. Lo irónico de dicha declaración es que Calderón es el jefe

superior a 4\% en 2000 a un promedio anémico de $0.6 \%$ de crecimiento anual en 2001-2002 (Porzecanski, 2009: 10).

14 De 2002 a 2006, en América Latina se registró una de las más altas tasas de crecimiento en más de dos décadas. Si descomponemos la demanda agregada de los tres sectores principales de la economía (externo, público y privado), podemos mostrar que la trayectoria de crecimiento se explica principalmente por el desempeño favorable del sector externo y, en menor medida, por el aumento de deuda del sector privado. Desde finales del decenio de 1990, América Latina ha sido capaz de reducir su déficit en la balanza comercial y, a partir de 2002, como consecuencia del auge de productos básicos, lograr un superávit (Petras y Veltmeyer, 2009). Lo anterior sucedió pese a que los gobiernos involucrados, principalmente en América del Sur, no proporcionaron ningún estímulo adicional para incrementar la demanda agregada (en la mayoría de los casos, los países optaron por reducir su déficit presupuestario, y en otros pocos, la política fiscal fue esencialmente contractiva). Una revisión reciente del desarrollo de estos países relaciona tal desarrollo con el boom de los productos básicos (2002-2006) (Pérez Caldentey y Verneng, 2008).

15 Guillén (2009), entre otros, señala que la recesión comenzó en América Latina durante el cuarto trimestre de 2008. "A pesar de ello, todavía en diciembre de 2008, la CEPAL preveía para 2009 un crecimiento del PIB del 1.9\%." Sin embargo, en abril de 2009 el mismo organismo estimó una contracción de $0.3 \%$ (ECLAC, 2009a), y en junio la modificó a una mayor de $-1.7 \%$ (El financiero, 2009). Agrega Guillén que "el FMI y el Banco Mundial coinciden en que la región entrará en recesión y que ésta afectará a economías tan importantes como Brasil, México, Argentina, Chile y Colombia”. Y prosigue señalando que durante el cuarto trimestre de 2008, "México, Brasil, Argentina y Chile registraron decrecimientos anualizados del PIB del $10.3 \%, 13.6 \%, 8.3 \%$ y $1.2 \%$, respectivamente". Y, en el primer trimestre de 2004, "las caídas se moderaron en Brasil, Chile y Argentina, pero se profundizaron en México al registrar un decrecimiento anualizado sin precedentes, del 21.5 por ciento".

16 En noviembre de 2008, cuando el espectro de la crisis global estaba generando gran preocupación aunque todavía no era motivo de alarma entre los círculos financieros y políticos, el 
de Estado del país más vulnerable, tanto por su cercanía como por su vínculo con la economía de los EEUU, epicentro de la crisis. En contraste, en el momento de la declaración pública de Calderón, diversos analistas predecían una pérdida de al menos 500000 puestos de trabajo -unos 175000 tan sólo en el primer semestre de $2009^{17}$. En marzo, la estimación de crecimiento del PNB de México para el año 2009 se redujo de -1.5\% a -3\% (La jornada, 17/03/2009). Aunque sólo 10 días más tarde, analistas mexicanos pronosticaron una caída de más de 5\% del PIB para el primer trimestre de 2009 (La jornada, 29/03/2009), pero, a finales de 2009, la caída real del PIB llegó a ser de casi 10 por ciento.

Otros gobiernos de América Latina no fueron tan rápidos en desdeñar los efectos de la crisis en la economía regional y local. Sin embargo, hubo quienes en el último trimestre de 2008 e incluso en 2009, mantenían en forma de autoengaño la creencia de que su país podría evitar la crisis haciendo uso de las reservas en moneda extranjera y de la deuda a corto plazo, que hasta el momento se mantenían relativamente saludables ${ }^{18}$. Esto fue cierto para los países de América del Sur, que

presidente Calderón, basando su pronóstico en un informe de Merrill Lynch del año anterior, fue muy optimista al decir: "no importa lo difícil que sea la crisis ya que probablemente es cíclica por lo que la dejaremos atrás rápidamente". Unos meses más tarde, en Davos, observó que México se encontraba en una buena posición para evitar la crisis en relación con otros países como Brasil, la India y Rusia; es más, incluso invitó a que los mexicanos vieran en la crisis los retos y oportunidades para transformar al país (La jornada, 06/01/2009).

17 Al regresar de Davos, el presidente Felipe Calderón se vio obligado a enfrentar la realidad de la crisis en México -en verdad Calderón ya había admitido en octubre de 2008 que "el grave caos mundial sí nos afectará", y para enfrentar la crisis propuso cinco políticas, entre las cuales destaca "ampliar el gasto en infraestructura" (Ortega, 2008)- y sostuvo que "mientras que el gobierno podría haber sido parte del problema en las crisis anteriores, ahora [bajo su administración] sería parte de la solución" (La jornada, 25/02/2009). Sin embargo, Calderón puntualizó su preocupación por no afectar a los mercados financieros y por el hecho de que se usaran medidas proteccionistas antimercado para evitar la próxima crisis de producción. Asimismo, estableció medidas de apoyo para mantener la solvencia de las instituciones financieras (la mayoría de propiedad extranjera), evitar las quiebras de empresas productivas, elevar la producción y la generación de empleo; también aumentó el gasto público para mejorar la distribución de los servicios sociales, prometiendo que para 2012 habría cobertura universal de educación, por lo que "el hijo de un empresario y un trabajador tendrán las mismas oportunidades educativas" (La jornada, 11/03/2009: 20).

18 Las exportaciones de América del Sur en el transcurso del auge de los productos básicos (20022008) fueron poco diversificadas y no dependientes del mercado de los EEUU. De manera que la fuerte demanda asiática hacia este tipo de productos, aun en 2008, sostiene la confianza de los gobiernos de la región de mantener un crecimiento en sus economías. Además, las enormes reservas de divisas generadas por los países de América del Sur hicieron que estuvieran menos preocupados por la volatilidad financiera -los cambios en la economía real fueron los que provocaron su reacción. Este retraso en la transmisión de la crisis a la economía real explica que 
se unieron al auge de exportación de sus materias primas en el mercado mundial. No obstante, el auge desapareció de la economía debido a la concentración de la ganancia por parte de las élites agrícolas y de los gobiernos que se beneficiaron sustancialmente de los altos precios y de los ingresos fiscales ${ }^{19}$.

Parece que Uruguay ha podido resistir los vientos de la crisis con un tasa de crecimiento sorprendentemente "robusta", de $11 \%$ en $2008^{20}$. Pero si los estudios económicos de la CEPAL (2009) y los análisis del Coloquio Internacional sobre la Crisis Mundial y América Latina en México (19-21 de enero, 2009)²1 son correctos, los países del Cono Sur no tienen motivos para ser optimistas. Sobre todo por el fracaso del G-8 para resolver la crisis desde el epicentro del sistema. Por lo que existe la posibilidad, o mejor dicho el riesgo, de que Uruguay tenga que luchar contra la propagación de los efectos en sus mercados financieros y en su economía real, que aún no llegan con toda su fuerza a esa nación.

En un reciente estudio de la CEPAL (2009) sobre las respuestas de los gobiernos de América Latina a la crisis global, se establece que ningún país de la región es inmune a la misma. Ello aplica incluso para aquellos que obtuvieron ventajas a partir del auge de exportaciones de sus materias primas, o los que se cuidaron de no gastar por encima de los límites de la deuda a corto plazo en el mercado mundial, y también para los que lograron acumular reservas ${ }^{22}$. Para los economistas de América Latina

cuando a Lula da Silva se le preguntó en septiembre de 2008 qué pensaba acerca de la crisis económica, haya respondido: “¿Cuál crisis? Vayan a preguntarle a Bush, ésta es su crisis, no la mía" (Fidler, 2009).

19 Para detalles al respecto, véase Petras y Veltmeyer, 2009.

20 Los demás países de la región también lograron un crecimiento del PNB en 2008, lo que sugiere que la tormenta de la crisis financiera mundial aún no ha golpeado a la región con el máximo vigor. En Argentina, el crecimiento del PIB se redujo a 6.8\% en 2008, en relación con el $8.7 \%$ de 2007; en Bolivia, fue de 5.8\%, aunque en realidad aumentó a 4.6\%; en Ecuador la tasa de crecimiento del PIB aumentó de 2.5\% a 6.5\%; en Brasil, sin embargo, pasó de 5.9\% hasta 5.7\%; en Chile, de $3.8 \%$ a 5.1\%; en Cuba cayó pasando de $12.1 \%$ en 2006 y $7.3 \%$ en 2007 a $4.3 \%$, y en México el crecimiento del PIB cayó de $4.8 \%$ en 2006 a 3.2\% en 2007 y a $1.8 \%$ en 2008 (CEPAL, 2009: 37ff).

21 Entre los participantes en este coloquio, organizado por la Universidad Autónoma Metropolitana-Iztapalapa en la ciudad de México, existe un consenso sobre "el sentido de que la crisis se manifiesta en toda América Latina, en diferentes formas, en diferentes países, regiones y sectores. Hasta la fecha no ha habido ningún esfuerzo coordinado para hacer frente a esta crisis [...] Los bancos centrales han aplicado una estrategia única de control de precios, a pesar de la inminente pérdida de puestos de trabajo y de la contracción de la economía. A pesar de que la crisis tiene su origen en el centro [del sistema] y que refleja los límites del modelo neoliberal aplicado en la región en las últimas décadas, la crisis no se origina desde fuera de la región, como algunos gobiernos señalan, sino que tiene un carácter claramente endógeno".

22 Según la CEPAL (2008), los principales mecanismos de transmisión de la crisis han sido el deterioro de los términos de intercambio, la disminución de las remesas de los migrantes y el retiro 
que se reunieron en la ciudad de México en enero de 2009, ningún país en la región está a salvo de la vorágine de la misma, pese a que la revista The Economist considere "esfuerzos valientes" a los realizados por México, Brasil, Argentina y Venezuela para controlar sus efectos. Independientemente de esto, es evidente que aquellos gobiernos y capitalistas que han acumulado una gran cantidad de deuda a corto plazo como porcentaje del total de sus reservas son los que se encuentran en riesgo y los más vulnerables ante la crisis (Bustillo y Helloso, 2009: 35ff; CEPAL, 2009).

De acuerdo con la Oficina en Washington de la CEPAL, los hechos muestran que desde octubre de 2008 América Latina ha experimentado los efectos de la crisis. La región ha tenido que lidiar con la contracción del crédito en su mercado, la desaceleración en sus flujos de capital, la dramática reducción en la inversión de portafolio, los grandes descensos en los índices de precios de acciones, los ajustes monetarios y el aumento de los spreads de deuda. El crecimiento del PIB de América Latina previsto para 2009 se redujo de $3.6 \%$ a $1.4 \%$ entre septiembre y diciembre de 2008 (Financial Times, 09/01/2009).

Las proyecciones más recientes del PIB per cápita en esta región estiman una caída de al menos $2 \%{ }^{23}$. En consecuencia, se espera una proliferación de las quiebras y, sin duda, la disminución del gasto público en servicios sociales. Aumentará el crédito público y los subsidios a los grandes bancos y empresas. También

masivo de los flujos privados de capital de los mercados financieros. Este organismo multilateral estimó que los términos de intercambio de la región cayeron un 15\% durante 2009 (2008: 22). Adicionalmente, México experimentó un fuerte descenso en los precios de los productos primarios; para febrero de 2009 estos precios habían caído respecto al pico de la expansión, de la siguiente manera: petróleo, 51\%; alimentos, 18\%; arroz, 50.6\%; maíz, 47.9\%; trigo, 41.9\%; metales, $49 \%$, y cobre, $37.9 \%$. En el caso de la disminución de las remesas de migrantes, los países más afectados serán México, Bolivia, Ecuador y la mayor parte de Centroamérica y del Caribe.

23 Como señala Guillén (2009), la situación de América Latina es bastante compleja, con graves dificultades a encarar en el futuro inmediato. El autor observa el camino de México, de Colombia y de los países más cercanos al Consenso de Washington, para "integrarse más con los EEUU, subordinarse a los organismos multilaterales y esperar a que pase el diluvio para reflotar el modelo neoliberal". Lo anterior quizá pueda resultar un escenario atractivo para algunos, pero hay que señalar que los costos sociales serán inmensos. Guillén no duda de que "se profundizarán la heterogeneidad estructural, la desigualdad social y la pobreza. Por otra parte, la ruta para los gobiernos autodefinidos como progresistas, que son la mayoría de la región, es difícil". Estos gobiernos "deberían perseverar, en un contexto mundial convulso, en su unidad; en la profundización de sus procesos de transformación económica y política internos; en la búsqueda de estrategias y políticas alternativas; en la ampliación de sus relaciones con las potencias emergentes (China, Rusia, la India, Irán, etc.); y en la concreción y fortalecimientos de esquemas de integración sur-sur". 
crecerá el desempleo, especialmente en los sectores de agrominerales y transporte (automóviles) y en los de exportación. Muchos de los empleados públicos serán despedidos o quizá experimenten una fuerte disminución en sus salarios. Los flujos financieros externos sufrirán la pérdida de miles de millones de dólares y euros y las remesas de los trabajadores en el extranjero también disminuirán. Ante esto, los especuladores extranjeros están retirando miles de millones de dólares de inversión para cubrir sus pérdidas en los EEUU y Europa.

Según el FMI, 40\% de la riqueza financiera de América Latina en 2008 -aproximadamente US \$220 000 millones- se ha perdido debido a la contracción en el mercado de valores, el mercado de activos y la depreciación de la moneda. Se espera que estas pérdidas contribuyan a la reducción en el gasto nacional en un 5\% en 2009.

En América Latina los términos de intercambio comercial se han deteriorado y los precios han caído, en algunos casos drásticamente; las importaciones son más caras, haciendo evidente el espectro del creciente déficit comercial (Financial Times, 09/01/2009: 7). El inicio de la recesión se puso de manifiesto en el caso de Brasil con la caída de 6.2\% en la producción industrial en noviembre de 2008 (Financial Times, 07/01/2009: 5). En ese entonces se podía pensar que América Latina estaba a punto de entrar en un periodo de profunda y prolongada recesión, sin que, al parecer, existiera un plan o programa para contrarrestar sus efectos negativos. Los gobiernos de la región-especialmente Chile, Perú y Colombia, que mucho dependen del flujo de inversión extranjera directa- tomaron acciones para proteger a sus mercados y reducir al mínimo su exposición al virus mortal, y de esta manera amortiguar el impacto de la crisis mediante diversas políticas anticíclicas (CEPAL News, 2009) ${ }^{24}$. Vale decir que hasta el momento estas medidas han tenido muy poco éxito, aunque la magnitud de la crisis es menor a la que preveían los economistas de la CEPAL (ECLAC, 2009a), quienes incluso la categorizan como la missing financial crisis (ECLAC, 2009a).

Los gobiernos de la región no son los únicos que han respondido a la crisis mundial: sectores de izquierda y organizaciones populares, que agrupan a sindicatos, diversas organizaciones de base y movimientos sociales de la región, han elaborado su propio análisis de la crisis mundial. Su argumento es que aunque tanto la producción

24 La respuesta inicial de los regímenes políticos de "centro-izquierda" a la profundización de la crisis se ha centrado principalmente en: 1) apoyar financieramente al sector bancario (Lula) y el recorte de impuestos a la exportación de agrominerales de alta calidad (Kirchner/ Lula); 2) brindar crédito "barato" a los consumidores para estimular las compras de automóviles (Kirchner), y 3 ) crear prestaciones, como la ayuda de desempleo temporal a los trabajadores despedidos de las pequeñas y medianas minas que han cerrado (Morales). 
como la crisis han sido originadas por el mundo financiero "virtual", en realidad la crisis refleja la caída del neoliberalismo o "el agotamiento de la ideología neoliberal", así como la debilidad de las condiciones de desarrollo capitalista en la región. Además, reconocen que aunque la crisis ha asumido múltiples y diversas formas, fundamentalmente se trata de una crisis de producción. Esto se pone en evidencia al observar sus efectos, tales como la pérdida masiva de puestos de trabajo, la erosión de los ingresos y las pensiones administradas bajo el velo de las instituciones financieras capitalistas, el recorte de los servicios públicos esenciales y la falta de acceso a la alimentación. Estos problemas están profundizando los efectos de la crisis con consecuencias sociales desastrosas.

\section{Los gobiernos, la izquierda y el pueblo responden a la crisis}

Se puede argumentar que aunque existan protestas masivas, la recesión en sí puede dar lugar a una reestructuración económica -hasta una transformación productiva y social- sin implicar necesariamente un cambio del sistema. En la fase inicial de respuesta a la crisis, los esfuerzos de la lucha de clases serán dirigidos a conservar los puestos de trabajo, prevenir los despidos masivos e incluso ocupar fábricas para defender el empleo. Esto puede ser acompañado por la exigencia de una mayor intervención del Estado, ya sea mediante subvenciones a las empresas o nacionalizaciones selectivas. El declive de la ideología neoliberal es inevitable, pero su sustitución inicial más probable es el "capitalismo de Estado" o un neoliberalismo menos excluyente, más pragmático y quizá maquillado con cara de un "socialismo democrático o democracia social" por parte del Posconsenso de Washington y la alianza entre centro-izquierda y sociedad civil.

De acuerdo con Petras (2009) -aunque hasta el momento los hechos no lo comprueben totalmente-, la respuesta más radical a la crisis se produce en los países más dependientes de las exportaciones de productos primarios y los más integrados a los mercados deprimidos de los EEUU y de la Unión Europea. Estos países incluyen, en particular, a México, Ecuador, Perú, Venezuela y Bolivia. Países como Chile, Argentina, Brasil y Colombia, con exportaciones más diversificadas y con un mayor mercado interno, también serán afectados por la recesión mundial, pero no de manera tan grave o abrupta como los demás países. Es probable que la recesión proceda por etapas, suavizada inicialmente por las reservas de divisas. También que la recesión se profundice bajo condiciones de fuga de capitales, pérdida de crédito y estancamiento de los mercados de inversión, así como una caída en las remesas. Los productores locales y los mercados de capital recibirán duros golpes. Desde esa perspectiva, a pesar de los 
pronósticos del Fondo Monetario Internacional de que la mayoría de los países de la región saldrán de la crisis en el año que viene, aún persisten las condiciones -y la estructura socioeconómica así como la política económica- que llevaron a ella, con la anticipación de una crisis del sistema más severa. Según la CEPAL, es asombroso (truly noteworthy) que ningún país en la región -en particular Brasil, Chile, Perú y Venezuela, que experimentaron una fuerte choque exógeno respecto a las ganancias por exportaciones, restricciones al acceso de los mercados de capital y una pérdida de capital-hasta ahora haya experimentado una crisis financiera o económica de escala mayor (ECLAC, 2009a: 17). Independientemente de lo anterior, los economistas de la CEPAL están conformes con la consideración de James Petras de que por falta de medidas "estructurales" (en vez de meramente contracíclicas) tomadas por la clase gobernante, el sector popular quedó vulnerable ante las fuerzas que conllevan un severo deterioro de sus condiciones socioeconómicas. En el transcurso de las crisis, casi 900000 personas, es decir, una cuarta parte de la población que en años recientes ya había escapado de la pobreza, gracias a la acción propia o por la nueva política social del Posconsenso de Washington, una vez más ha caído en ella (ECLAC, 2009b: 18).

Según Petras (2009), una radicalización de la izquierda podría afianzarse en caso de que fallen los planes de estímulo económico contracíclicos y de obras públicas, y que la recesión se profundice y se prolonge. La clave aquí es la estructura de las relaciones sociales de producción en los centros socioeconómicos de la crisis, y las dinámicas de esta estructura en la formación de grupos organizados que proyecten líderes capaces de articular el descontento local y de vincularlo a un plan nacional antiimperialista-socialista (Petras, 2009). Dadas las actuales circunstancias, la recesión abre una oportunidad para el resurgimiento de movimientos de masas, lo que a su vez crea las condiciones para una reactivación y renovación de los movimientos, incluso aquéllos con una orientación socialista ${ }^{25}$. La recesión mundial, afirma Petras, "no sólo socava aún más lo que queda de la legitimidad del neoliberalismo, sino que también reta la configuración de la clase capitalista".

Habrá quien pueda cuestionar las ideas de Petras sobre las fuerzas y dinámicas sociopolíticas de la crisis, pero no hay duda de que el espectro de un colapso económico y el fracaso de los bancos y del sistema financiero están despertando condiciones de

25 En el periodo 2007-2008, nuevos movimientos de masa surgieron en países donde 10 años antes no los había. Por ejemplo, los movimientos militantes en Colombia, Perú y Costa Rica excedieron a aquéllos de Argentina y Bolivia en el mencionado periodo. En Colombia, mientras las guerrillas se reagruparon en una retirada táctica, indígenas, estudiantes y trabajadores organizaron muchas marchas para confrontar y luchar en contra del régimen asesino de Uribe. 
una política nueva -en forma de un "nacionalismo de Estado"- como preludio a un cambio posiblemente radical en la política dominante en la región y a una relación desequilibrada entre el Estado y el mercado, favoreciendo al primero. Podemos entender en estos términos el fenómeno de Hugo Chávez y su proyecto de construir el "socialismo del siglo XXI" - proyecto compartido por razones coyunturales más que por coincidencia ideológica por Evo Morales y Rafael Correa en el afán de conformar un Estado plurinacional. En estas condiciones -véanse también Argentina y Brasil-y en el contexto de un nacionalismo de tipo nuevo, graves tensiones en las relaciones entre América Latina y los EEUU son inevitables, pero también prometedoras para el proyecto socialista (Katz, 2008).

El proceso de crisis y el de sus respuestas está en curso, y a pesar de que algunas soluciones están mal definidas, se observa una tendencia emergente en la izquierda política y académica y en las organizaciones de los sectores populares de discutir e incluso negociar sus propuestas con los gobiernos "progresistas" o cuasisocialistas de la región. Las negociaciones se llevan a cabo con gobiernos como los de Chávez, Correa y Morales, incluso con los de Ignacio Lula Da Silva, Cristina Kirchner y Michelle Bachelet, estos últimos neoliberales pragmáticos o sociales, a los que de ninguna manera podría acusárseles de ser socialistas. Las propuestas a discusión con estos gobiernos incluyen:

- un aumento en el gasto social y la inversión en infraestructura, y una reorientación de la política del Banco Central hacia la generación de empleo, primeras recomendaciones de los economistas estructuralistas e institucionalistas reunidos en enero de 2009 en la ciudad de México;

- la creación y extensión de un sistema regional de banca y de instituciones financieras de desarrollo como el Banco del Sur (una propuesta que cuenta con el consenso de todos los sectores);

- la extensión y profundización de la Alianza Bolivariana para los Pueblos de Nuestra América (ALBA), proyecto alternativo de comercio regional propuesto inicialmente por Hugo Chávez y que ahora incluye una alianza regional entre Venezuela, Bolivia, Ecuador y Cuba, así como Nicaragua y Honduras (y posiblemente El Salvador después de la reciente victoria del FSLN, ya que ALBA cuenta con consenso por parte de la izquierda ${ }^{26}$;

26 El lado débil de la izquierda, en el contexto del mundo en recesión es, en palabras de Petras (2009), "su fragmentación, dispersión y conflictos internos entre los partidos de izquierda en 
- un modelo alternativo de la producción local de alimentos y de la seguridad alimentaria, basado en el mantenimiento de los medios de vida sustentables de los pequeños productores campesinos (modelo promovido por Vía Campesina), y

- el socialismo en una forma u otra ${ }^{27}$ (con el Estado centralizado en algunas propuestas, y, en otras, descentralizado para permitirle al poder popular la toma de decisiones públicas), y la socialización de los medios sociales de producción y consumo. Esta propuesta -avanzada por algunos sectores del movimiento obrero, como el Sindicato Mexicano de Electricistas (SME), que hace hincapié en el hecho de que los trabajadores no tienen nada que ver con la causa de la crisis, pero todo con ponerle fin - promueve la movilización social de todos los sectores de la izquierda, tanto del Estado, en el caso de Venezuela (y tal vez Bolivia y Ecuador), como de la sociedad civil, de los trabajadores sindicalizados, de los movimientos sociales y de todos los sectores con una postura crítica respecto del neoliberalismo. La propuesta también considera la creación de alianzas regionales y órganos de coordinación como la Coordinadora de Movimientos Sociales (CMS) en Ecuador.

Las políticas contracíclicas recomendadas por los economistas de orientación estructuralista o institucionalista, con la intención de recrear un Estado keynesiano de bienestar, son coherentes con las recomendadas por otros grupos de economistas de la izquierda socialdemócrata. De hecho, muchos gobiernos "progresistas" o de

América Latina, lo que limita su capacidad de competir por el poder estatal". Los movimientos de masa y los sindicatos han sido debilitados y divididos o, peor aún, cooptados por los regímenes de centro-izquierda (Petras y Veltmeyer, 2009). Estos regímenes han usado los movimientos como pretexto para neutralizar y despolitizar a los movimientos de masa. Lula, por ejemplo, cooptó a la mayoría de los líderes del sindicato de la CUT, su secretario general se convirtió en ministro del Trabajo. También debilitó al MST mediante la inyección de fondos a sus cooperativas, rompió los compromisos prometidos, utilizó represión y sobre todo canalizó millones de reales brasileños hacia la élite agrícola. Sin embargo, con la recesión, el control de Lula va a ser severamente probado. Esto no es exclusivo de Brasil, ya que al mismo tiempo que se incremente el desempleo, el control político de centro-izquierda en América Latina será debilitado. Además, mientras se incremente el desempleo y las agroexportaciones disminuyan, el descontento masivo irá en aumento.

27 La forma en que el "socialismo" se configura en Venezuela es resumida por Rafael Correa en los siguientes términos: "...la acción colectiva a nivel social se realiza a través del Estado, la representación institucionalizada de la sociedad... [Pero] no es la única forma colectiva [o pública] de acción social, esto es otro gran desafío. Tenemos que crear comunidades para que la acción colectiva surja de los barrios y de las ciudades" (Correa, "Socialismo del siglo XXI", NINA Comunicaciones, 2007: 26). 
centro-izquierda en la región, formados a partir del desencanto respecto del neoliberalismo, ya han adoptado estas políticas. Por ejemplo, el resumen de la CEPAL (ECLAC, 2009a) sobre las políticas anticíclicas, es decir contra la crisis, adoptadas por los distintos gobiernos de la región en 2008, señala que 16 de los 21 países en América Latina aumentaron el gasto público en infraestructura. Otros cinco gobiernos promovieron la creación de empleo. También 14 gobiernos han mantenido o incluso aumentado el gasto público dirigido a aspectos sociales. Adicionalmente, seis gobiernos redujeron sus reservas internacionales, una medida similar a la adoptada por los gobiernos del G-8; 15 aumentaron la liquidez en moneda nacional y ocho en moneda extranjera (ECLAC, 2009a). Sin embargo, en la respuesta que estos gobiernos han dado a la crisis queda reflejada su interpretación de la misma, es decir, esencialmente como una crisis del mercado financiero y como un problema de la política fiscal-monetaria.

Hubo países que adoptaron políticas estructurales, derivadas de un entendimiento contrario a la explicación monetaria o fiscal de la crisis, que han sido de especial importancia. Estas medidas se llevaron a cabo por los "gobiernos progresistas" de centro-izquierda, principalmente en Venezuela, país que desde 1999 es el foco de la izquierda latinoamericana y eje de una nueva alianza con Cuba y los gobiernos de centro-izquierda de Bolivia y Ecuador. Las medidas incluyen, entre otras: un nuevo mecanismo de comercio intrarregional (ALBA), la creación de un mecanismo institucional para promover el desarrollo de las economías de la región (el Banco del Sur) y la renacionalización de los recursos naturales y empresas económicas en los sectores estratégicos. Vale señalar que tanto la alianza como las políticas mencionadas fueron implementadas desde antes de la crisis. Más bien representan una respuesta al imperialismo de los EEUU y el modelo de globalización neoliberal que este país ha promovido en toda la región desde la década de 1980.

También algunas políticas adoptadas por estos países son similares a las que se han puesto en marcha en los centros del capital, como lo son las tímidas políticas de nacionalización de los bancos e instituciones financieras en los EEUU y en el Reino Unido, es decir, ¡la socialización fáctica de las pérdidas privadas a cambio de un rescate financiero! Pero para los países de América Latina, la política de renacionalizar los recursos del país y las empresas de sectores estratégicos se inserta en la necesidad de buscar un sistema alternativo al capitalismo (Panitch y Gindin, 2009). Un sistema concebido por Hugo Chávez como el socialismo del siglo XXI. Todavía no hay consenso en cuanto a la forma que este socialismo pueda asumir, tampoco, como insiste Chávez, un modelo preestablecido, sólo se dispone de un acuerdo de principio sobre la necesidad de crear un nuevo modelo de desarrollo, para una sociedad nueva "plenamente humana", una 
sociedad de iguales que conduzca a un "nuevo mundo de justicia, dignidad e igualdad, sólo posible con el socialismo" (Chávez, 2007: 247).

Por lo que se puede observar, hay indicios de que estos cambios "estructurales" en la organización del desarrollo nacional y regional pueden ayudar a los países y a sus pueblos a sostenerse a pesar de los estragos derivados del proceso de reestructuración. Proceso que, hasta el momento, ha destruido hasta unos US \$50 billones en la economía mundial, con graves consecuencias para los que tienen que trabajar o ganarse la vida en la economía real ${ }^{28}$. Normalmente, tal proceso de reestructuración de capital golpea con más fuerza a los más pobres, aquellos que se ubican en los márgenes y por lo tanto más alejados del "centro", y que al mismo tiempo son incapaces de protegerse a sí mismos de sus consecuencias. La única alternativa para que el pueblo se defienda de la crisis y de su reestructuración es desconectarse, en lo posible, de éste, y movilizar activamente las fuerzas de resistencia en contra del sistema y en favor de un mundo nuevo.

\section{Una Minga de la Resistencia: La elaboración de políticas desde abajo}

El 29 de febrero de 2009, una alianza regional de indígenas, campesinos y movimientos sociales en Bolivia convocó a su pueblo para organizar una Minga de la Resistencia, en asociación con "otros pueblos y procesos” en la región (Abya Yala, 2009)29. Minga es un término quechua que significa "acción colectiva", elemento de gran importancia para indígenas, pobres y mestizos en los Andes. La llamada a participar en una minga, es decir, la acción colectiva a escala local y mundial, gana fuerza en las referencias culturales para estos pueblos que comparten una historia de subyugación. El hecho de que estos grupos convoquen a una minga habla sobre la necesidad de realizar un trabajo político que al mismo tiempo conduzca a la acción colectiva ${ }^{30}$.

28 Una serie de publicaciones académicas recientes sobre las perspectivas de la crisis de producción, agravada por la crisis financiera mundial, es editada por la colección de ensayos Peasants and Globalization (Akram-Lodhi y Kay, 2009) y se centra en la manera en que las políticas neoliberales que rigen al mundo contemporáneo han profundizado la crisis agraria. Otro estudio, con un enfoque más general en el desarrollo de las sociedades en el orden mundial neoliberal, es elaborado por Bello (2009).

29 Esta alianza incluye a la Coordinadora Andina de Organizaciones Indígenas (CAOI), la Coordinadora de Organizaciones Indígenas de la Cuenca Amazónica (COICA), el Consejo Indígena de Centro América (CICA), el Movimiento Sin Tierra del Brasil (MST), Vía Campesina, las organizaciones que componen el Pacto de Unidad en Bolivia; y diversas organizaciones indígenas de Colombia, Ecuador y Perú. Todas éstas se reunieron el 26 de febrero de 2009, en la sede del Pacto de Unidad, en La Paz.

30 En su Informe Mundial de 2008, el Banco Mundial pronosticó que los pobres del campo sólo tienen tres opciones en la búsqueda de alternativas para salir de su pobreza en condiciones de 
El pensar y actuar en búsqueda de alternativas al desarrollo capitalista y al neoliberalismo, fuentes indudables de la actual crisis mundial, está en marcha en el sector popular de los diferentes países de la región. Véase, por ejemplo, la convocatoria (20 de enero de 2009) de los Movimientos Sociales de América en el Foro Social Mundial en Belem. Partiendo de un diagnóstico de la profunda crisis del capitalismo en la actual coyuntura, los agentes y organismos del capitalismo y el imperialismo tratan de descargar la crisis sobre los pueblos. Ante tal circunstancia, la representación de una amplia coalición regional de los movimientos sociales de América anunció la necesidad, y su intención, de crear un "proyecto de vida de los pueblos frente [...] al imperialismo", también de perseguir una forma popular de "integración regional" (ALBA) "desde abajo", cuya principal bandera sea la "solidaridad social como prioridad frente al imperialismo" 31 .

De acuerdo con esta perspectiva popular, la crisis mundial no es un asunto de regulación de los mercados financieros, sino una cuestión social relacionada con la producción. Implica crear modos de vida sustentables, cuidando el empleo y el precio de los alimentos, que bajo las condiciones de la crisis mundial se encuentran en un alza vertiginosa. En su momento, el ex secretario Ejecutivo de la CEPAL, José Luis Machinea, señaló que el persistente incremento de los precios de los alimentos está golpeando especialmente a los más pobres de América Latina y el Caribe. Además se espera un empeoramiento en la distribución de los ingresos. De hecho, se estima que 10 millones de personas viviendo en pobreza podrían convertirse en indigentes. Esta catástrofe se configura sin tomar en consideración a las personas que ya eran pobres o indigentes antes de que estallara la crisis mundial.

Existen otros ejemplos de acción popular contra las crisis de producción y alimentaria, como la alianza obrero-campesina en México. Esta alianza se formó para hacer asequibles los alimentos disponibles a los campesinos y a los trabajadores en las ciudades ${ }^{32}$. En este contexto, otro indicador de los efectos negativos de la crisis ha sido el incremento en el precio de la tortilla ${ }^{33}$, por el cual portavoces de esta alianza anunciaron que los productores miembro entregarán a los trabajadores y a sus familias

crisis. Cada opción (migración, trabajo, actividad agrícola) implica una respuesta estratégica que requiere actuar de manera individual como miembro de una familia, y no en torno a su ubicación en la estructura social. No incluye en su marco analítico la posibilidad de una acción colectiva orientada a cambiar el sistema o el modelo neoliberal que lo rige. Para un enfoque crítico sobre este análisis del BM, véanse Akram-Lodhi, 2009; y Veltmeyer, 2009.

31 Véase alba@movimientos.org.

32 Véase La jornada on line, 24/02/2009.

33 Véase el análisis de la dinámica de precios por Bello, 2008.

\section{Desarrollo}


las mercancías a precios de costo de producción, por lo menos $20 \%$ por debajo de las empresas comerciales, y sin cobrarles los impuestos. Efraín García Bello, director de la Confederación Nacional de Productores Agrícolas de Maíz de México (CNPAMM), y signatario de la alianza de producción, señaló que las acciones de este tipo están encaminadas a apoyar a la economía de los trabajadores en las zonas urbanas y a los habitantes en el campo.

En el mismo sentido, distintas organizaciones del movimiento campesino en México, incluyendo aquéllas cercanas a la burocracia, propusieron al gobierno que se incluyera dentro de su plan anticrisis una política de producción local de maíz, arroz, leche, aceite vegetal y productos de cerdo, entre otros, con la intención de poner fin a la libre importación de productos agrícolas bajo el Tratado de Libre Comercio de América del Norte (TLCAN), que ha sido -como asegura el Ejercito Zapatista de Liberación Nacional (EZLN)- la causa de una crisis en la producción agrícola y una sentencia de muerte para los campesinos pobres.

En lo que respecta a la producción local y a las importaciones de aceite vegetal, el presidente de la Cámara de Senadores de la Comisión de Desarrollo Rural señaló que en este caso la política del gobierno relativa a la eliminación de los derechos de importación ha puesto en peligro los medios de subsistencia y el empleo directo de hasta 10000 personas en el sector y, además, 30000 empleos indirectos (La jornada, 17/03/2009).

Se concluye, entonces, que la cuestión más importante de esta y otras acciones realizadas por el sector popular se relaciona con el hecho de si la izquierda política e intelectual estará a la altura del desafío formulado por Abya Yala. Es decir, de si existe la capacidad y voluntad de apoyar activamente las fuerzas de cambio revolucionario que se están formando desde el sector popular, y que buscan una alternativa real al desarrollo mercantil y capitalista.

\section{Conclusiones}

Nuestro argumento, construido con base en la hipótesis de una propensión del sistema capitalista a la crisis, se puede resumir en las siguientes propuestas: 1) la crisis de la década de 1970 no tenía una forma financiera, sino que fue una crisis del sistema capitalista de producción, con respuestas estratégicas y estructurales que incluyen la globalización de capital en su forma neoliberal; 2) la crisis en sus condiciones es multidimensional; 3) la crisis global tiene su origen en la desconexión entre la economía financiera y la producción -la financiarización-; 4) como toda crisis, crea fuerzas de cambio y abre una "oportunidad" para cambiar la "estructura" de las condiciones 
socioeconómicas; 5) las respuestas estratégicas producidas en América Latina a la "oportunidad" ofrecida por la crisis, han sido inadecuadas; 6) la clase política gobernante -incluidos los gobiernos de izquierda y centro-izquierda (en Venezuela, Argentina, Brasil, Chile, Bolivia)-, al concebir la crisis en forma errónea, considerándola sólo una crisis financiera transmitida desde el exterior, respondió con una política contracíclica destinada a reducir la vulnerabilidad de su economía respecto del exterior, pero minimizó los efectos de los mecanismos de transmisión de la crisis; en cambio, 7) el movimiento popular, incluidos sus intelectuales orgánicos y la izquierda social, entendió que no se trata de una crisis financiera sino de una crisis de la producción capitalista, cuya raíz ha de buscarse en el fondo del sistema (grosso modo, es posible apreciar en ello elementos de un nuevo consenso posneoliberal); y 8 ) a pesar de este consenso emergente, las organizaciones populares no han podido responder adecuadamente a la crisis, ni como acción colectiva encaminada a la resistencia que asimismo conduzca al derrocamiento del sistema, ni en cuanto a la construcción de un modelo alternativo.

De nuestro análisis se desprenden dos conclusiones. La primera tiene que ver con las dinámicas mismas de la crisis, es decir, con las fuerzas de cambio liberadas por la crisis y las respuestas estratégicas a estas fuerzas, que tienen su horizonte en la reestructuración del sistema o de las relaciones sociales de producción. En cuanto a los encargados de diseñar las políticas en América Latina así como gran parte de los economistas a quienes consultan -ya sean de orientación neoliberal, cepalista, neoinstitucionalista, etc.-, consideran que la causa de la crisis es externa. No obstante, cabe señalar que desde la crisis de la deuda externa de los ochenta, los países de América Latina se insertaron pasivamente a la globalización neoliberal; dicha inserción es la causante principal del estancamiento económico experimentado durante las últimas décadas -y también de la actual crisis que asola a la región en todas sus dimensiones. Los movimientos populares, con su base en el nuevo proletariado (y semiproletariado) y en las comunidades indígenas y campesinas, aún no han podido concertar una estrategia adecuada (para pasar de la resistencia a la ofensiva) ni construir un modelo económico alternativo; sin embargo, tanto sus intelectuales orgánicos como los grupos de izquierda al menos entienden que la crisis es inherente al sistema capitalista y por lo tanto difieren de la postura de los economistas de la CEPAL, quienes se enfocan en identificar "los mecanismos principales de transmisión" de la crisis para poder contrarrestar sus efectos estructurales y su funcionamiento.

La segunda conclusión es que ni una mejor gobernabilidad global ni una regulación más eficaz sobre el capital son los caminos para salir de la crisis. Tampoco lo es la construcción de un mejor balance entre mercado y Estado, ni la adecuación 
entre la producción y la acumulación de capital (desfinanciarización). Para salir de la crisis se requiere una nueva correlación de fuerzas y una movilización activa de la población en contra del modelo neoliberal y el sistema capitalista. Se necesita un Estado posneoliberal; no una forma de "desarrollo", es decir neoliberalismo, más incluyente -como propone la CEPAL (Sunkel e Infante, 2009)-, sino el abandono total del modelo. No se trata de buscar una reforma más del sistema, ni un ajuste en su institucionalidad para suavizar sus efectos y humanizar el proceso, sino una transformación social. Sin duda, la fuerza social y política para llegar a esta meta no está en la clase política, ni en la captura de esta clase a los instrumentos del poder político concentrado en el Estado. La salida de la crisis en sus múltiples dimensiones requiere que se derrumbe el sistema que la reproduce, mediante la movilización eficaz de las fuerzas sociales y políticas en el sector popular. No se trata únicamente de que la acción colectiva y concertada de todas las fuerzas resista las maniobras de la clase dominante para imponer el sistema: se trata de construir una alternativa social, económica e histórica.

\section{Bibliografía}

Abya Yala-Movimientos Indígenas, Campesinos y Sociales, "Diálogo de Alternativas y Alianzas", Minga Informativa de Movimientos Sociales, La Paz, 26 de febrero de 2009.

Akram-Lodhi, A. H. "(Re)imagining agrarian relations?" The World Bank Development Report 2008: A griculture for Development. Development and Change, vol. 39, núm. 6, 2008, pp. 1145-1161.

Akram-Lodhi, A. H. y C. Kay, Peasants and Globalisation: Political Economy, Rural Transformation and the Agrarian Question, Londres, Routledge, 2009.

Bárcena, Alicia, Preliminary Overview of the Economies of Latin America and the Caribbean, Santiago, ECLAC, 2009.

Beinstein, Jorge, "Acople depresivo global (radicalización de la crisis)", Servicio Informativo ALAI-Amlatina, 13/0409, Buenos Aires, 2009.

Bell Lara, José, Cuba in the 1990s, La Habana, José Martí, 2009.

Bello, Walden, "The global collapse: A nonorthodox view", Z Net, 22 de febrero de 2009.

Bernanke, Ben, Essays on the Great Depression, Princeton University Press, 2000.
Brenner, Robert, The Economics of Global Turbulence, Londres, Verso, 2000.

Bulmer-Thomas, Victor, The Economic Model in Latin America and its Impact on Income Distribution and Poverty, Nueva York, St. Martin's Press, 1996.

Bustillo Inés y Helvia Helloso, The Global Financial Crisis: What Happened and What's Next, Washington DC, ECLAC-Washington Office, febrero de 2009.

CEPAL, "Crecimiento de América Latina y el Caribe retrocedería a $-0.3 \%$ en 2009, según la CEPAL", 6 de abril de 2009, http://www. eclac.org

, Balance preliminar de las economías de América Latina y el Caribe, Comisión Económica para América Latina-Naciones Unidas, Santiago de Chile, 2008.

CEPAL News, vol. XXIV, núm. 2, febrero de 2009.

Chávez, Hugo R., "El socialismo del siglo XXI", en Néstor Kohan (comp.), Introducción al pensamiento socialista, Bogotá, Ocean Sur, 2007.

Desai, Meghnad, Marx's Revenge: The Resurgence of Capitalism and the Death of Statist Socialism, Londres, Verso, 2004. 
ECLAC (Economic Commission of Latin America and the Caribbean), The Reactions of Latin American and Caribbean Governments to the International Crisis: An Overview of Policy Measures up to 30 January 2009, Santiago, Naciones Unidas, 2009a.

Social Panorama of Latin America: Briefing Paper, Santiago, Naciones Unidas, 2009b.

, Productive Transformation with Equity, Santiago, Naciones Unidas, 1990.

El financiero, "Estima CEPAL caída de 1.7\% del PIB en América Latina", El financiero, México, 11 de junio de 2009.

Foster, John Bellamy y Fred Magdoff, "Financial implosion and stagnation: Back to the real economy", Monthly Review, vol. 60, núm. 6, diciembre de 2008, pp. 1-15.

Friedland, W. H. y C. G. Rosberg Jr., African Socialism, Stanford, Stanford University Press, 1964.

Fröbel, Folker, Jürgen Heinrichs y Otto Kreye, The New International Division of Labour. Structural Unemployment in Industrialised Countries and Industrialisation in Developing Countries, Cambridge, Cambridge University Press, 1980.

George, Susan, The Lugano Report: On Preserving Capitalism in the 21st Century, Londres, Pluto Press, 1999.

Glynn, A., A. Hughes, A. Lipietz y A. Singh, "The rise and fall of the Golden Age", en Stephen Marglin y Juliet Schor (comps.), The Golden Age of Capitalism: Re-interpreting the Post-War Experience, Oxford, Clarendon Press, 1990.

Guillén, Arturo, "En la encrucijada de la crisis global", ALAI-Amlatina, 18 de junio de 2009.

, Mito y realidad de la globalización neoliberal, México, Miguel Ángel Porrúa editores-UAM-I, 2007.

Harvey, David, A Brief History of Neoliberalism, Oxford University Press, 2005.

Lipietz, Alain, Mirages and Miracles: The Crisis in Global Fordism, Londres, Verso, 1987.

Magdoff, Harry y Paul Sweezy, The Irreversible Crisis, Nueva York, Monthly Review Press, 1988.
Ocampo, José Antonio, "The macroeconomics of the Latin American economic boom", CEPAL Review, 93, diciembre de 2007.

, "Latin America and the world economy in the long twentieth century", en K. S. Jomo (ed.), The Great Divergence: Hegemony, Uneven Development, and Global Inequality, Nueva York, Oxford University Press, 2006.

Ocampo, José Antonio, K. S. Jomo y Sarbuland Khan (comps.), Policy Matters: Economic and Social Policies to Sustain Equitable Development, Londres, Orient Longman y Penang, Third World Network, 2007.

Ortega, Eduardo, "Lanza Felipe Calderón cinco medidas para enfrentar la crisis", El financiero, México, 9 de octubre de 2008.

Panitch, Leo y Sam Gindin, "From global finance to the nationalization of the banks: Eight theses on the economic crisis", Global Research, Centre for Research on Globalization, 25 de febrero de 2009.

Pérez Caldentey, Esteban y Matías Verneng, Back to the Future: Latin America's Current Development Strategy, Nueva York, Monthly Review Press, 2008.

Petras, James y Henry Veltmeyer, Espejismos de la izquierda en América Latina, Buenos Aires, Lumen, 2009.

, Empire with Imperialism, Londres, Zed Books, 2005.

, Globalization Unmasked: Imperialism in the 21st Century, Halifax-Londres, Fernwood Publications-ZED Press, 2001.

Porzecanski Arturo, "Latin America: The missing financial crisis", Studies and Perspectives, núm. 6, Washington DC, ECLAC, 2009.

Veltmeyer, Henry, Illusions and Opportunities: Civil Society in the Quest for Social Change, Halifax, Fernwood Publications, 2007.

"The World Bank on agriculture for development: A failure of imagination or the power of ideology?", Journal of Peasant Studies, vol. 36, núm. 2, 2009, pp. 393-410.

World Bank, Latin America and the Global Crisis, Washington DC, 2008.

Worsley, Peter, The Three Worlds: Culture and World Development, The University of Chicago Press, 1984. 